\title{
Transport of Particulate Organic Matter and Dissolved Organic Matter from Land to Ocean in Hokkaido, Japan
}

\author{
M. Jahangir Alam ${ }^{1,2}$, S. Nagao ${ }^{1}$ and M. Emran Quayum ${ }^{3 *}$ \\ ${ }^{1}$ Graduate School of Environmental Earth Science, Hokkaido University, Sapporo, 060-0810, Japan. \\ ${ }^{2}$ Graduate School of Geographical Sciences, Southwest University, Chongqing 400715, P.R. China \\ ${ }^{3 *}$ Department of Chemistry, Dhaka University, Dhaka-1000, Bangladesh.
}

(Received : 22 May 2014; Accepted : 16 July 2014)

\begin{abstract}
Both $\Delta^{14} \mathrm{C}, \delta^{13} \mathrm{C}$ for the particulate organic matter (POM) and 3-Dimensional Excitation and Emission Matrix spectroscopy (3D-EEM) for the dissolved organic matter (DOM) were used to study transport behavior from land to ocean in Hokkaido, Japan. The ${ }^{14} \mathrm{C}$ values of the Tokachi POC (particulate organic carbon) show similar variations to Ishikari. However, the variation range of the Tokachi of ${ }^{14} \mathrm{C}$ is smaller than that of the Ishikari POC. $\delta^{13} \mathrm{C}$ values for the Ishikari showed larger variation range than those of the Tokachi. The POC during spring snow-melting for the Ishikari and in autumn during heavy rain fall for the Tokachi were distinctive in the correlations of POC, ${ }^{14} \mathrm{C}$, and $\delta^{13} \mathrm{C}$.There were two different pathways in the correlations of POC content, $\Delta^{14} \mathrm{C}$, and water discharge for both river systems. The significant pathway during snow-melting found in the Ishikari and at autumn during heavy rain fall for the Tokachi. The Tokachi and the Ishikari River showed similar variations patterns of dissolved organic carbon (DOC) concentrations and relative fluorescence intensity (RFI). The run-off point of DOC and FA-like materials is similar to POC. Therefore, characteristics and export of POC and DOC may be controlled by water discharge in small rivers in sub-arctic zone. The both rivers showed averaged POC flux from $1.43 \sim 1.51 \times 10^{10} \mathrm{~g} / \mathrm{yr}$, DOC flux of $0.98 \sim 2.32 \times 10^{10} \mathrm{~g} / \mathrm{yr}$, and fulvic-like materials-carbon (FAC) flux of $0.70 \sim 1.22 \times 10^{10} \mathrm{~g} / \mathrm{yr}$. The percentages of POC, DOC, and FAC flux in two rivers during snow-melting and heavy rainfall were $78 \sim 95 \%$ and $25 \sim 42 \%$, respectively. The watersheds of the Ishikari and Tokachi are important in transport of POC from land to ocean, especially during snow-melting and heavy rain event.
\end{abstract}

Keywords: POM, DOM, Rivers, Land, Ocean, flux

\section{Introduction}

River systems transport $0.1 \sim 0.9 \times 10^{15} \mathrm{~g} / \mathrm{yr}$ of organic carbon of which $50 \%$ is particulate organic carbon (POC) and $50 \%$ dissolved organic carbon $(\mathrm{DOC})^{6,11}$. Estimated organic carbon (POC and DOC) fluxes are in uncertainties because the used data set are mainly from few large rivers of a particular region and other rivers data are calculated from extrapolation ${ }^{6}$. Carbon discharge and transport patterns vary among rivers and watershed conditions, which include geographical, land use, and hydrological features ${ }^{6}$. The characteristics and concentrations of organic carbon depend on time, space, and seasons ${ }^{6,22}$. Dynamics of organic carbon and its fate in river systems are unknown because organic carbon exhibits tremendous temporal and spatial variations in physico-chemical characteristics ${ }^{19}$. Water discharges in some small river systems are very low and

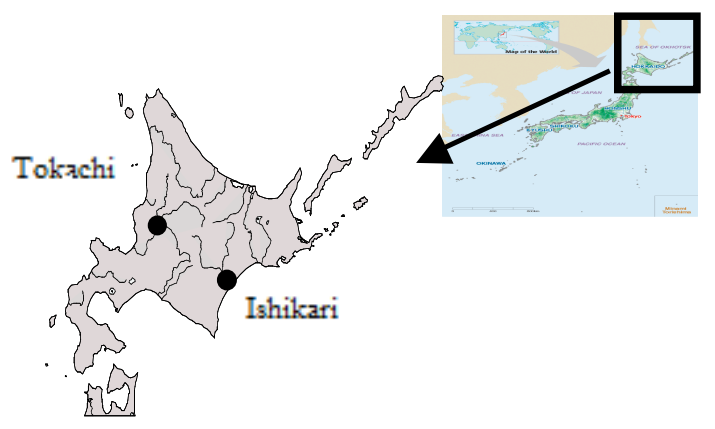

Fig.1. Sampling sites difficult to estimate its flux basis on organic carbon concentrations. Researchers showed that organic carbon discharges vary with water discharge temporally and spatially ${ }^{20}$. Researchers analyzed the characteristics of organic matter in river waters $1,14,15,17,18$. Therefore, we need transport behavior that is very important for the interpretation of temporal and spatial variability of organic carbon transport and flux from land to coastal ocean and expected to provide enough information to researchers for the regional and global carbon cycle. To understand transport behavior in river systems we must obtain information on residence time, patterns of transport and discharge of POC and DOC. Both $\Delta^{14} \mathrm{C}$ and $\delta^{13} \mathrm{C}$ values have been proven to be simple and useful parameters to study POM sources and residence time ${ }^{9,18,19}$. Three-dimensional excitation and emission matrix fluorescence spectroscopy (3D-EEM) has been used to understand the sources and dynamics of humic substances in aquatic ecosystems ${ }^{2}$. Therefore, 3D-EEM fluorescence spectroscopy can be used as convenient and easy method to identify FA like materials in rivers. This study applied carbon isotopic ratios $\left(\Delta^{14} \mathrm{C}\right.$ and $\left.\delta^{13} \mathrm{C}\right)$ to POM and 3-D EEM spectroscopy to DOM in the Ishikari and the Tokachi Rivers to understand transport behavior in the Ishikari and Tokachi Rivers, in Hokkaido, Japan and estimated its flux from land to ocean.

\section{Materials and Methods Sampling sites}

The Ishikari River runs through the low land in eastern Hokkaido (Fig.1). It has a catchments area of $14330 \mathrm{~km}^{2}$

*Author for Correspondence. e-mail: relyeq@yahoo.com 
and is $268 \mathrm{~km}$ long. The main types of land use are forest, agriculture and urban. The monthly average water discharge ranges from $280-500 \times 10^{6} \mathrm{~m}^{3} / \mathrm{month}^{10}$. Monthly mean winter precipitation is $46-105 \mathrm{~mm}$ and the snow depth is from 38$108 \mathrm{~cm}$ from December to late April ${ }^{8}$. The Tokachi River runs through the south-eastern Hokkaido. It flows through Tokachi plain, which includes old and new alluvial fans and streams terraces. Geological features of the plain are mainly volcanic rocks with unconsolidated sediments along. It has catchments of $9010 \mathrm{~km}^{2}$ and is length is $156 \mathrm{~km}$ long. Monthly mean winter precipitation is $42-60 \mathrm{~mm}$ and snow depth is $11-51 \mathrm{~cm}$ from December to late April ${ }^{8}$. The monthly average water discharges range from $200-330 \times 10^{6}$ $\mathrm{m}^{3} /$ month $^{10}$.

\section{Sampling}

River waters were collected once a month at a water flow observatory, Iwamizawa-Bridge of the Ishikari River and Moiwa-Bridge of the Tokachi River from April to December in 2004 and January to July in 2005 for the Ishikar River and April, June, October, December in 2004 and January to June, August, September in 2005 for the Tokachi. About $70 \mathrm{~L}$ of waters was collected in polythene containers, which were then transferred to the laboratory. Turbidity was measured during sampling using a nephelometer (U-21XD; Horiba Ltd.); it is expressed in NTU units. Suspended materials in river waters samples were concentrated using a single-flow continuous flowing centrifuge with a flow rate of $15 \mathrm{~L} / \mathrm{h}^{21}$. These solids samples were dried at $40^{\circ} \mathrm{C}$. We calculated suspended solid concentrations in milligram-per-liter units, dividing the dried solids weight by the volume of centrifuged water. About 6 litter of water sample was collected into a glass bottle during sampling. The collected water samples were filtered with Whatman GF/F glass fiber filters after precombustion at $550^{\circ} \mathrm{C}$ for two hours. The filtered samples were stored in a freezer at $-30^{\circ} \mathrm{C}$ until analysis. Isolated fulvic acids data from the Tokachi River and Bekanbashi River waters have been used according to the method of Nagao et $a l .{ }^{15}$ for the calculation of FA- like materials concentrations.

\section{Analysis}

The POC contents for suspended particles isolated through continuous flowing centrifugation were determined using a total organic carbon analyzer (WR-112; LECO Corp.). Prior to analysis, calcium carbonate was removed by adding $0.1 \mathrm{M}$ $\mathrm{HCl}$, rinsing withy Milli $\mathrm{Q}$ water and subsequent drying. We measured POC content by conflow-MS spectrometer for all of the rivers. The obtained POC contents were expressed as wt.\% unit (gC/100g suspended solid dry basis). The POC concentrations were expressed using the following equation: POC concentration $(\mathrm{mg} / \mathrm{L})$

POC $=($ wt \% $) \times$ Mass of suspended solids $(\mathrm{mg}) /$ Centrifuged water volume (1)

Radiocarbon $\left({ }^{14} \mathrm{C}\right)$ measurements were performed using accelerator mass spectrometry (AMS) at the National Institute for Environmental Studies, Japan. The ${ }^{14} \mathrm{C} /{ }^{12} \mathrm{C}$ and ${ }^{13} \mathrm{C} /{ }^{12} \mathrm{C}$ ratios were measured using an AMS system (Model 15 SDH-2; NEC Corp.). The $\Delta^{14} \mathrm{C}$ was defined as the deviation from the modern standard in parts per thousand (\%). The $\delta^{13} \mathrm{C}$ was defined as the deviation from the PDB standard in parts per thousands (\%o ${ }^{20}$.

DOC concentrations were measured by a Shimadzu MarkIV TOC analyzer. A Hitachi F-4500 fluorescence spectrometer with a $150 \mathrm{w}$ ozone free xenon lamp was used to obtain 3D-EEM spectra of the aquatic humic substances and natural waters according to the method of Nagao et al. ${ }^{14}$. The spectra were collected at an excitation wavelength from $200 \mathrm{~nm}$ to $500 \mathrm{~nm}$ and an emission wavelength from 200 $\mathrm{nm}$ to $600 \mathrm{~nm}$ at $5 \mathrm{~nm}$ intervals. Photo-multiplier voltage was set to 400 voltages. Relative fluorescence intensities (RFI) of the samples were expressed in terms of quinine standard unit (QSU). FA like materials-carbon (FAC) concentrations were calculated from the calibration equations between standard fulvic acid concentrations isolated from the Tokachi and Bekabeshi River and relative fluorescence intensity (RFI). FAC\% was calculated based on FAC and DOC concentration. The POC, DOC, and FAC flux were estimated by the following equation using respective concentration ${ }^{6}$.

OC flux $(\mathrm{g} /$ day $)=$ OC concentration $\times$ water discharge $\left(\mathrm{m}^{3} /\right.$ day $)$ $\left(\mathrm{m}^{3} /\right.$ day $)$.

OC flux $(\mathrm{g} /$ day $)=$ OC concentration $\times$ water discharge

The annual fluxes in 2004 and 2005 for the Ishikari and Tokachi were estimated through the relationship between cumulative transport of organic carbon and sampling day.

\section{Results and Discussion}

Variations in POC amounts, carbon isotopic ratios, DOC, fluorescence properties, and flux POC content and concentrations were ranged $1.18-7.76 \% 0.2-7.6 \mathrm{mg} / \mathrm{L}$ in the Ishikari River, respectively. These values were from 2.94$5.73 \%, 0.1-25.0 \mathrm{mg} / \mathrm{L}$ in the Tokachi River, respectively (Table). The $\Delta^{14} \mathrm{C}$ and $\delta^{13} \mathrm{C}$ showed variations from $-364 \%$ to $-103 \%$, $-34.2 \%$ o to $-22.8 \%$ in the Ishikari River and $242 \%$ to $-111 \%$, $-29.4 \%$ o to $-26.4 \%$ in the Tokachi River, respectively (Table). DOC concentrations in the Ishikari River were ranged from 1.88 - $4.89 \mathrm{mg} / \mathrm{L}$. DOC concentrations in the Tokachi River were ranged from 1.17 $4.28 \mathrm{mg} / \mathrm{L}$. DOC concentrations were within the reported values ${ }^{6,22}$. The RFI in the Ishikari River were ranged from 10 QSU - 30 QSU. The RFI in the Tokachi ranged from 7 34 QSU. The variations patterns of DOC concentrations and RFI were somewhat different one another. FA-like carbon concentrations (FAC) ranged from 0.78 to $2.75 \mathrm{mg} / \mathrm{L}$ for the Ishikari and from 0.48 to $3.09 \mathrm{mg} / \mathrm{L}$ for the Tokachi. Similar spatial variations in FAC were observed in the study of Nagao et al. ${ }^{16}$ in the Kuji River waters.

Relationships in POC content, $\Delta^{14} C$ and $\delta^{13} C$ values, DOC, and fluorescence properties

The $\Delta^{14} \mathrm{C}, \delta^{13} \mathrm{C}$ and POC content values in spring during snow-melting in April and May are distinctive than summer 
to winter for the Ishikari. There were also distinctive values in $\Delta^{14} \mathrm{C}, \delta^{13} \mathrm{C}$, and POC content in spring snow-melting and in autumn during heavy rainfall for the Tokachi (Fig.2).
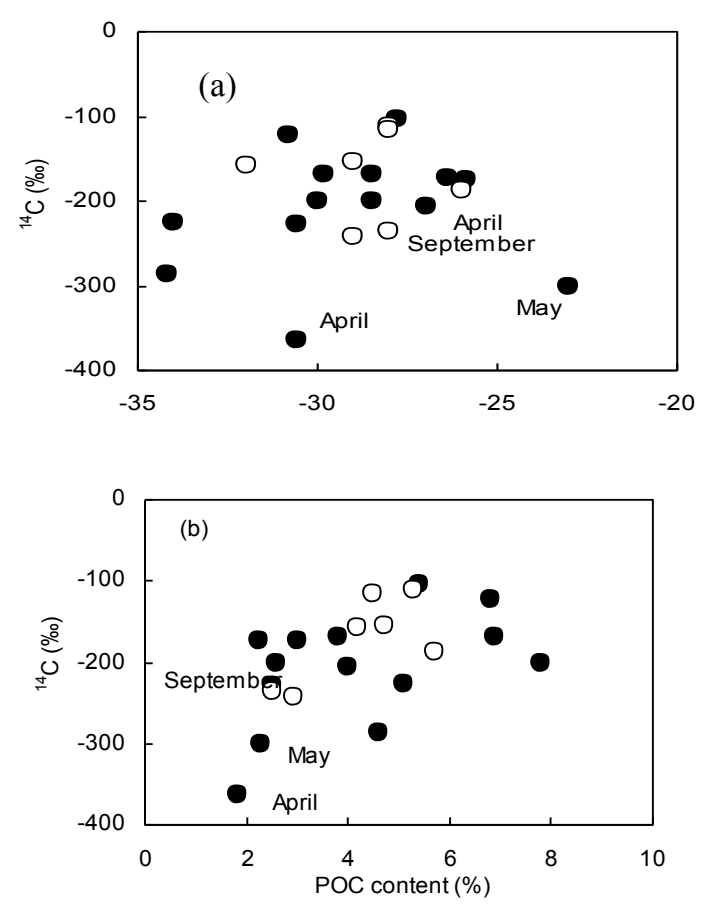

Fig. 2. The relationship $\Delta{ }^{14} \mathrm{C}, \delta^{13} \mathrm{C}$ (a) and POC contents, $\Delta{ }^{14} \mathrm{C}(\mathrm{b})$. The closed circles for the Ishikari and open circle for the Tokachi

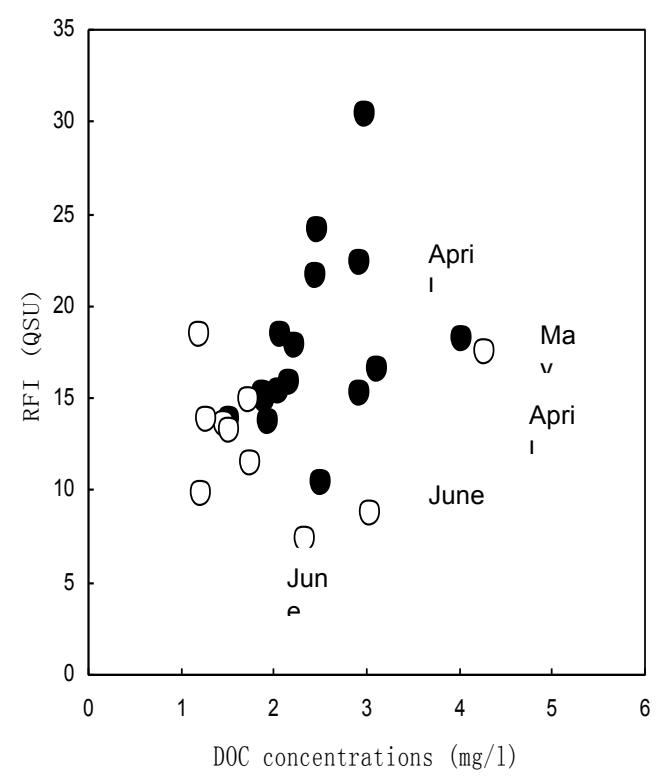

Fig. 3. Relationship in DOC and RFI. The closed circles for the Ishikari and open circle for the Tokachi
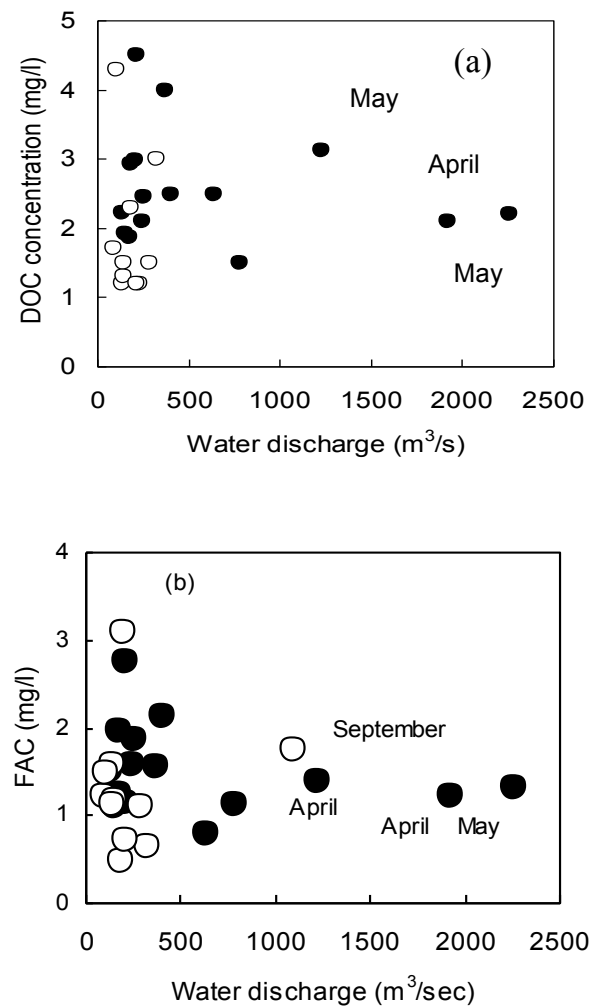

Fig. 4. Relationships in $\Delta^{14} \mathrm{C}$, $\mathrm{POC}$ concentrations and water discharges. The closed circle for Ishikari and open circle for the Tokachi
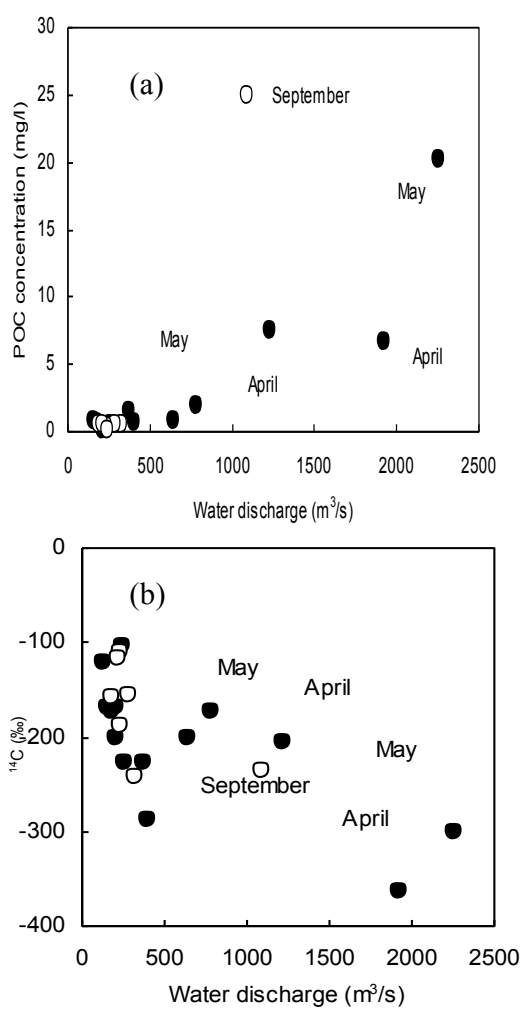

Fig. 5 Relationships in DOC, FAC concentrations and water discharges. The closed circle for Ishikari and open circle for the Tokachi 
Fig. 3 shows the relationships in DOC and RFI. The spring and early of summer values are deviated more than other samples in the Tokachi River. Similarly, the spring snow melting and early of summer samples are more deviated from the correlation of the other samples in the Ishikari River.

Relationships in POC concentrations, $\triangle^{14} C$, DOC concentrations, FAC concentrations and water discharge

Fig.4.Shows relationships in POC concentrations, $\Delta{ }^{14} \mathrm{C}$ versus water discharges. The POC in spring snow-melt for the Ishikari and in the autumn for the Tokachi are deviated from the relationship.

Fig.5 shows relationships of DOC concentrations, FAC concentrations versus water discharges. The DOC and FAC in spring snow-melt samples for the Ishikari and the in autumn heavy rainfall for the Tokachi samples are largely deviated from the correlations.

\section{Transport behavior of POM and DOM in the Ishikari and} the Tokachi Rivers

This study observed POM through a pathway at water discharge of $<500 \mathrm{~m}^{3} / \mathrm{sec}$ from summer to winter for the Ishikari. These values might be for POM characteristics and indicate recent organic matter ${ }^{3,4}$. Another significant pathway was at water discharge of $>500 \mathrm{~m}^{3} / \mathrm{sec}$ during snow-melting for the Ishikari and heavy rainfall for the Tokachi. About $83 \mathrm{~mm}$ heavy rainfall was occurred ${ }^{8}$. This pathway transport $1.31-39.39 \times 10^{8} \mathrm{~g} /$ day of POC which are about eight times higher than the transport of another pathway. The snow -melting for the Ishikari and heavy rain fall higher water discharges for the Tokachi transport $78 \%$ and 95\% POM, respectively. The decreased POC contents during snow-melt and heavy rainfall indicate much of dilutions occurred through the addition of higher amounts of minerals from watershed and river bottom sediments. The dilution can depend on water discharge and watershed erosion. These distinctive values might be for POM characteristics. Therefore higher water discharge during spring snow-melt and heavy rainfall might be one of controlling factors in rivers. The possible mechanisms are river bank erosion or re-suspension of bottom sediments of soil organic matter during higher water discharge period ${ }^{6}$. During higher water discharge river bank erosion and resuspension are common phenomena ${ }^{12,13}$. This study found a distinctive pathway of DOC and FAC transport in spring during snow-melt for the Ishikari during heavy rainfall for the Tokachi similar to POC. This pathway transports from $1.38-4.23 \times 10^{8} \mathrm{~g} /$ day of DOM and from $0.76-2.71 \times 10^{8}$ $\mathrm{g}$ /day of FAC which is $42 \%$ for the Ishikari and $26 \%$ for the Ishikari, respectively. DOM might be from soil organic matter or sediments organic matter through watershed soil erosion or re-suspension ${ }^{6,7,22}$. The annual average flux of POC, DOC, and FAC were $1.43 \times 10^{10}, 2.32 \times 10^{10}, 1.20 \times$ $10^{10} \mathrm{~g} / \mathrm{yr}$ in the Ishikari River and $1.51 \times 10^{10}, 0.98 \times 10^{10}$, $0.70 \times 10^{10} \mathrm{~g} / \mathrm{yr}$ in the Tokachi, respectively. These observations were different from those of Raymond and Bauer ${ }^{19}$ and Hedges et al. ${ }^{5}$. These two studies are reversing one another and make controversy.

\section{Conclusion}

This study has been investigated the transport behavior of organic matter (POM and DOM) from land to ocean in the Ishikari and Tokachi Rivers. This study found that the concentrations and flux of POC, DOC, and FAC varied with water discharge in both of the river systems. During the transport from river to ocean, the POC, DOC, and FAC concentrations and flux were varied through two different pathways and water discharge. POC, DOC and FAC at water discharge $<500 \mathrm{~m}^{3} / \mathrm{sec}$ from summer to winter for the Ishikari and from summer to spring for the Tokachi have narrow role to transport organic carbon from land to ocean due to their characteristics. On the other hand POC, DOC and $\mathrm{FAC}$ at water discharge at $>500 \mathrm{~m}^{3} / \mathrm{sec}$ in spring during snow-melting higher water discharge for the Ishikari and in autumn during heavy rainfall for the Tokachi have extensive and wide role to transport organic carbon from land to ocean due to their distinctive characteristics through different sources and mechanisms. $78-95 \%$ of annual flux of POC occurred in these periods in two rivers. DOC and FAC fluxes were $26-42 \%$ in these significant periods. The Ishikari and the Tokachi are important of potential source of organic materials (POM and DOM) although, these are comparatively small rivers.

\section{Acknowledgements}

The authors thank Mr. H. Yamamoto for assisting with sampling. This work was funded partly by a Grant-in-Aid for Science Research, No. 15310002 and 21st Century Centre of Excellence (COE) program of the Ministry of Education, Culture, Sports, Science and Technology, Japan. The authors are also thankful to Prof. Yuan Daoxian, Dr. Youngjun Jiang and Li Young, Southwest University, China for their valuable suggestions.

\section{References}

1. Baker, A., 2002. Spectrophotometric discrimination of river dissolved organic matter. Hydrol. Proc., 16: 3203-3213.

2. Coble, P.G., 1996. Characterization of marine and terrestrial DOM in seawater using excitation-emission matrix spectroscopy. Mar. Chem. 51, 325-346.

3. Degens, E.T., March 8-12, 1982.Transport of carbon and minerals in major world rivers part 1, Proceedings of a workshop arranged by scientific committee on problems of the Environment (SCOPE) and the United Nations Environment Program (UNEP) at Hamburg University.

4. Hobbie, J.E., G.E. Likens, 1973. Output of phosphorus, dissolved organic carbon, and fine particulate carbon from Habbard Brook watersheds. Limnol. Oceanogr. 18, 734-742.

5. Hedges, J. I., J. R. Ertel, P. D. Quay, P. M. Grootes, J. F. Richey, A. H. Devol, G. W. Farwell, F.W. Schmidt, E. Salati, 1986. Organic carbon-14 in the Amazon River system. Science, 231, 1129-1131.

6. Hope, D., M. F. Billett, M.S. Cresser, 1994. A review of the export of carbon in river water: fluxes and processes. Environ. Pollut. 84, 301-324.

7. Hope, D., M. F. Billett, R. Milne, T. A. W. Brown, 1997. Export of organic carbon in British rivers. Hydrol. Proc. 11, $325-344$ 
8. Japan Meteorological Agency, 2004. http://www.data.kishou.go.jp/.

9. Kao,S. J., F. J. Lin, K. K. Liu, 2003. Organic carbon and nitrogen contents and their isotopic compositions in surfacial sediments from the east China Sea shelf and the southern Okinawa Trough. Deep-Sea Res. II, 50, 1203-1217.

10. Ministry of Land, Infrastructure, and Transport, Japan. http://wwwl.river.go.jp/

11. Meybeck, M., 1982. Carbon, nitrogen, and phosphorus transport by World Rivers. Am. J. Sci., 282, 401-405.

12. Morris, A.W., M. J. Howarth, 1998. Bed stress induced sediment re-suspension. Continental shelf Res., 18, 12031213.

13. Alam, M. J., S. Nagao, T. Aramaki, Y. Shibata, M. Yoneda, 2007. Transport of particulate organic matter in the Ishikari river, Japan during spring and summer. NIMB. 259, 513-517.

14. Nagao, S., Y. Suzuki, M. Nakaguchi, K. Hiraki, Senoo, 1997. Direct measurement of the fluorescence characteristics of aquatic humic substances by a three-dimensional fluorescence spectrometer. Bunseki Kagaku., 46: 335-342.

15. Nagao, S., N. Fujitake, H. Kodama, T. Matsunaga, H. Yamazawa, 2003.Association of Am with H Chem., 255, 459464.
16. Nagano, T., N. Yanase, T. Tsuduki, S. Nagao, 2003. Particulate and dissolved elemental loads in the Kuji River related to discharge rate. Environ. Int., 28, 649-658.

17. Nagao, S., T. Matsunaga, Y. Suzuki, T. Ueno, 2003. Characteristics of humic substances in the Kuji River waters as determined by high-performance size exclusion chromatography with fluorescence detection. Water Res. 37, 4159-4170.

18. Nagao, S., T. Usui, M. Yamamoto, M. Minagawa, M. Iwatsuki, A. Noda, 2005. Combined use of $\Delta^{14} \mathrm{C}$ and $\delta^{13} \mathrm{C}$ values to trace transportation and deposition processes of terrestrial particulate organic matter in coastal marine environments. Chem. Geol. 218, 63-72.

19. Raymond, A., J. E. Bauer, 2001. Use of $\Delta{ }^{14} \mathrm{C}$ and $\delta^{13} \mathrm{C}$ natural abundances for evaluating riverine, estuarine, and coastal DOC and POC sources and cycling: A review and synthesis. Org. Geochem. 32, 469-485.

20. Stuiver, M., H. A. Polach, 1977. Radiocarbon. Radiocarbon. 19, 355-64.

21. Stedmon, C. A., S. Margaker, R. Bro, 2003. Tracing dissolved organic matter in aquatic environments using a new approach to fluorescence spectroscopy. Mar. Chem. 82, 239-254.

22. Thurman, E.M. 1985. Organic Geochemistry of Natural waters. Martinus Nijhoff/Dr W. Junk Publishers, Dordrecht. 
